\title{
P09- I 8. Cw*0303/0304 HIV specific CTL response toward GagYL9 select for HIV escape variants with low fitness that is compensated by intra-codon variation
}

\author{
I Honeyborne ${ }^{4}$, A Leslie 4 , H Crawford ${ }^{4}, \mathrm{CM}_{\text {Rousseau}}^{2}$, JI Mullins², \\ BD Walker ${ }^{3}$, P Goulder ${ }^{1}$ and JG Prado*4
}

\author{
Address: ${ }^{1}$ University of Oxford, Oxford, UK, ${ }^{2}$ University of Washington/School of Medicine, Washington, WA, USA, ${ }^{3}$ Partners AIDS Research \\ Center/Massachusetts General Hospital, Boston, MA, USA and ${ }^{4}$ University of Oxford/irsiCaixa Fundation, Badalona, Spain \\ * Corresponding author
}

from AIDS Vaccine 2009

Paris, France. 19-22 October 2009

Published: 22 October 2009

Retrovirology 2009, 6(Suppl 3):PI3I doi:10.II86/I742-4690-6-S3-PI3I

This abstract is available from: http://www.retrovirology.com/content/6/S3/PI3I

(c) 2009 Honeyborne et al; licensee BioMed Central Ltd.

\section{Background}

The potential importance of HLA-C CD8+ specific responses in control of HIV replication is still unknown and controversial. Many known CTLs are restricted by HLA-A or HLA-B but only a small number are restricted by HLA-C. This study examines the impact on HIV-1 immune escape and viral fitness of a CTL response restricted by HLA-Cw*0303/0304 (YL9) in a very conserved region of HIV Gag p24.

\section{Methods}

HIV CD8+ specific responses to a panel of overlapping peptides (OLP) were measured by INF- $\gamma$ ELISPOT and HIV Gag sequences were obtained from HLA-Cw*0303/0304 subjects with chronic HIV infection $(n=80)$. The avidity of RI9 responses was measured by IFN- $\gamma$ Elispot assay to serial diluted peptides for each variant (T303V, T303I, T303A). Plasmids containing YL9 mutations were constructed by site-directed mutagenesis. Viral replication kinetics were measured by GFP expression. DNA from a patient with T303V was amplified by PCR and cloned into pGEM. Gag proviral clones were analyzed and phylogenetic analysis carried out.

\section{Results}

$60 \%$ of $\mathrm{Cw}^{*} 0303 / 0304 \mathrm{HIV}$ individuals have a pattern of Gag recognition focus on OLPs containing the YL9 epitope. There is a strong association between the expres- sion of $\mathrm{Cw}^{*} 0303 / 0304$ and changes at the C-terminal of the epitope YVDRFFKTL 296-304 (YL9) from Thr-303 to Val, Ile and Ala with $(\mathrm{p}=1.62 \times 10-10)$. In addition, changes T303I and T303A in YL9 decrease epitope avidity by 5 -fold and show a significant reduction of replicative capacity. However, the selection of T303V restores viral fitness and in vitro recognition. Clonal analysis suggests the mutational pathway of $\mathrm{T} 303 \mathrm{~V}$ selection through WT and T303A intermediates.

\section{Conclusion}

These studies demonstrate that HLA-Cw*0303/0304 YL9 CTL responses targeting p24 can drive viral immune escape and changes in viral replication to similar extent to other HLA-B described responses. This data highlight the importance to define relevant HLA-C responses that drive HIV evolution and impact in viral fitness. 